\title{
Análise acerca do boicote dos estudantes aos exames de avaliação do ensino superior
}

\author{
THIAGO MIGUEL SABINO DE PEREIRA LEITÁO* \\ GABRIELA MIRANDA MORICONI** \\ MARIÂNGELA ABRÃO*** \\ DAYSE SOUZA DA SILVA****
}

\section{RESUMO}

Este estudo analisa o fenômeno popularmente denominado de boicote aos exames que compóem o sistema de avaliação do ensino superior no Brasil, dando ênfase ao Exame Nacional de Desempenho dos Estudantes (Enade). Ao fazê-lo, evidencia a magnitude do boicote ao longo do tempo, entre as instituições públicas e privadas, por tipo de boicote. Investigando o último triênio de avaliação do Enade, a análise econométrica identifica as variáveis que mais afetam a decisão do aluno ao adotar esse comportamento. Essas análises permitiram traçar um perfil do estudante que adere ao fenômeno. Como principal conclusão, o estudo

* Coordenador Geral de Projetos Especiais para a Graduação (MEC) (thiago.leitao@mec.gov.br).

** Coordenadora Geral de Instrumentos e Medidas Educacionais (Inep/MEC) (gabriela.moriconi@inep.gov.br).

*** Pesquisadora Tecnologista em Informaçóes e Avaliaçóes Educacionais (Inep/MEC) (mariangela.abrao@inep.gov.br).

**** Pesquisadora Tecnologista em Informações e Avaliações Educacionais (Inep/MEC) (dayse.silva@inep.gov.br). 
aponta que o boicote, quando analisado de forma geral, não se mostra significativo, uma vez que o percentual de ocorrência nunca foi superior a 3,5\%, mas quando analisado por curso a incidência desse fenômeno apresentou grandes variações. O presente artigo também revela algumas possíveis motivaçóes para esse comportamento, entre elas a insatisfação do aluno com o curso e/ou a instituição.

Palavras-chave: Avaliação da educação, Ensino superior, Enade, Comportamento, Alunos.

\section{RESUMEN}

Este estudio analiza el fenómeno popularmente denominado de boicot a los exámenes que componen el sistema de evaluación de la enseñanza superior en Brasil, dando énfasis al Examen Nacional del Desempeño del Estudiante (Enade). Al hacerlo, se pone en evidencia la magnitud del boicot a lo largo del tiempo, entre las instituciones públicas y privadas, por tipo de boicot. Al investigar el último trienio de evaluación del Enade, el análisis econométrico identifica las variables que más afectan la decisión del alumno al adoptar tal comportamiento. Estos análisis permitieron trazar un perfil de los estudiantes que adhieren a dicho fenómeno. Como principal conclusión, el estudio señala que el boicot, cuando se lo analiza de forma general, no se muetra significativo, ya que el porcentaje de ocurrencia nunca fue superior al $3,5 \%$, pero al analizarlo por curso la incidencia de ese fenómeno presentó grandes variaciones. El presente artículo también revela algunos posibles motivos para tal comportamiento, entre ellos, la insatisfacción de los alumnos con el curso y/o la institución.

Palabras clave: Evaluación de la educación, Enseñanza superior, Enade, Comportamiento, Alumnos.

\section{ABSTRACT}

This study examines the phenomenon popularly known as a boycott of exams that make up the evaluation system of higher education in Brazil, focusing on the National Assessment Examination of Student Performance (Enade). Thus, it highlights the magnitude of the boycott over time, between public and private institutions, by type of boycott. Investigating the last three years of the Enade assessment, econometric analysis identifies the variables that mostly affect a student's decision to adopt this behavior. These tests allowed us to draw a profile of the student who adheres to this phenomenon. As its main conclusion, the study suggests that the boycott, when analyzed in an overall way, does not appear significant, since the percentage of occurrence was never more than $3.5 \%$, but when analyzed by course, the incidence of this phenomenon showed wide variations. This article also reveals some possible reasons for this behavior, including the student's dissatisfaction with the course and/or institution.

Keywords: Evaluation of education, Higher education, Enade, Behavior, Students. 


\section{INTRODUÇÃO}

A Lei de Diretrizes e Bases da Educaçáo Nacional (LDB), Lei no 9.394 de 20 de dezembro de 1996 (Brasil, 1996), prioriza os processos de avaliação, visando à melhoria da qualidade do ensino, propondo critérios para a regulação do setor. A partir da sanção da LDB, a avaliaçáo da educação superior assume lugar de destaque entre as políticas educacionais, seja como norteadora de suas diretrizes mais amplas, seja como orientadora de açóes efetivas dos agentes governamentais.

Um sistema de avaliação da educação superior objetiva, primordialmente, oferecer informaçôes de qualidade para subsidiar a tomada de decisôes de indivíduos e organizaçóes direta ou indiretamente envolvidos com esse nível de ensino. Em linhas gerais, podem ser apontados como principais interessados em um sistema de avaliação da educação superior: os atuais e os potenciais alunos e suas famílias, os futuros empregadores dos profissionais egressos desses cursos, os agentes reguladores, as próprias instituiçóes de ensino superior (IES), bem como os profissionais que nelas atuam ${ }^{1}$.

$\mathrm{O}$ principal, mas não necessariamente o único interesse dos alunos (atuais $\mathrm{e}$ potenciais), suas famílias e empregadores está diretamente relacionado aos resultados finais dos cursos, ou seja, em identificar quais deles têm melhores condiçôes de formar bons profissionais para o mercado de trabalho. Isto porque, de posse desses dados, os potenciais alunos podem escolher as instituiçôes em que tentarão ingressar, relacionando com essas informaçóes aspectos como preço e localização, entre outros; os atuais alunos podem utilizar os bons resultados de seu curso ao se candidatar a uma vaga de estágio e/ou de emprego. Os maus resultados podem ser utilizados para cobrar melhorias da instituição de ensino; e os futuros empregadores têm mais um subsídio para decidir qual profissional contratar.

Já para instituiçóes de ensino superior, para os profissionais que nelas atuam e para os órgãos reguladores, medir somente a qualidade do profissional egresso dos cursos não é suficiente, pois a qualidade desse profissional não é um indicador direto do trabalho da instituição. Um curso que recebe alunos com formação prévia deficiente pode realizar um excelente trabalho e, ainda assim, não ter seus ex-alunos entre os melhores profissionais. Para Dias, Horiguela e Marchelli (2006, p.461), mesmo que as instituiçôes que recebem os alunos menos preparados se empenhem

\footnotetext{
${ }^{1}$ Para Harvey e Newton (2004), a beleza da abordagem, do ponto de vista do governo, é que a garantia de qualidade assegura não só a responsabilização, mas pode ser usada para motivar um grau de cumprimento das políticas públicas ou para controlar a expansão do setor privado.
} 
na recuperação dos déficits de aprendizagem, elas terão poucas chances de se equiparar às instituiçóes que recebem os alunos mais bem preparados. Para eles, "a qualidade do aluno é essencialmente diferente da qualidade de ensino, mas ambas se confundem na prática”.

Portanto, é muito importante saber quanto o curso contribui para a formação dos alunos, permitindo que as instituições de ensino alterem suas práticas, caso constatem pouca contribuição, e, aos reguladores, que definam critérios mínimos de qualidade para orientar essas instituiçôes, e, se necessário, aplicar sançóes.

O Brasil é o único país a aplicar um exame nacional de cunho obrigatório aos estudantes como um dos principais instrumentos que compóem o sistema de avaliação da educação superior.

Entretanto, tal instrumento de avaliação, por vezes, é contestado por alunos e instituiçóes por ser demasiadamente dependente do aluno. $\mathrm{Na}$ mídia, encontram-se declaraçóes de estudantes que afirmam ser injusto o peso que esse exame coloca sobre eles, uma vez que o objetivo final é avaliar o curso e não o aluno. Por outro lado, algumas instituiçóes de ensino superior reclamam que os alunos não teriam nenhum incentivo para se comprometer com a prova, o que afetaria o resultado de seus cursos.

Para Paiva (2008, p.42), "a implantação de políticas públicas de avaliação da educação superior brasileira é atividade que, indiscutivelmente, desencadeia manifestações favoráveis e críticas severas". Somente a avaliação contínua dessas políticas e a realização dos ajustes necessários é que asseguram o sucesso e a manutenção delas. $\mathrm{O}$ autor ainda afirma que a avaliação do desempenho acadêmico, como um dos componentes da política pública de avaliação da educação superior brasileira, por meio de um exame nacional, não é atividade pouco complexa. O sucesso do processo depende, sobremaneira, do comprometimento de todos os sujeitos envolvidos. Entretanto, os estudantes destacam-se como membros mais importantes quando a avaliação em questão é de desempenho acadêmico.

Fato é que toda vez que ocorre aplicação de prova para avaliação do ensino superior - inicialmente o Exame Nacional de Cursos (ENC) ou Prováo, e posteriormente o Exame Nacional de Desempenho dos Estudantes (Enade) - gera discussóes sobre a provável falta de participação ou envolvimento dos alunos no processo avaliativo - comumente denominado de "boicote".

O objetivo do presente artigo é, portanto, avaliar o fenômeno chamado popularmente de "boicote". O texto está dividido em 4 seções. A próxima seção aborda a avaliação dos cursos de ensino superior no Brasil. A seção 3

90 • Est. Aval. Educ., São Paulo, v. 21, n. 45, p. 87-106, jan./abr. 2010 
expóe a análise dos dados referentes ao boicote e, em seguida, na seção 4, são apresentadas as considerações finais.

\section{A AVALIAÇÃO DOS CURSOS DE ENSINO SUPERIOR NO BRASIL}

O processo de avaliação da educaçáo superior no Brasil se dá por meio do Sistema Nacional de Avaliação da Educação Superior (Sinaes), criado em 14/04/2004 como substituto do modelo de avaliação implantado em 1996, o Exame Nacional de Cursos (ENC) ou Prováo ${ }^{2}$, e objetiva aferir tanto a qualidade acadêmica do profissional egresso quanto a contribuição do curso para a sua formaçáo.

Os principais instrumentos de avaliação de cursos do Sinaes são o Enade e a avaliaçáo in loco, feita por especialistas que visitam as instituiçóes de ensino superior. Os processos de avaliação são coordenados pela Comissão Nacional de Avaliação da Educação Superior (Conaes), e o Instituto Nacional de Estudos e Pesquisas Educacionais Anísio Teixeira (Inep) é responsável pela parte operacional desse processo.

O Enade é um exame aplicado aos alunos ingressantes ${ }^{3}$ e concluintes $^{4}$ de cursos de graduação, de áreas definidas anualmente pelo MEC, com periodicidade trienal de aplicação a cada curso. $\mathrm{O}$ exame é composto de 40 questóes no total, sendo 10 da parte de formaçáo geral, comum aos estudantes de todos os cursos selecionados, e 30 do componente específico, diferenciado para cada um dos cursos de graduação. Ambas as provas contêm questóes discursivas e de múltipla escolha nas duas partes. Além do caderno de provas, recebido no momento da realização do exame, os alunos selecionados recebem previamente, em sua residência, um questionário socioeconômico que deve ser preenchido e entregue no dia da prova.

Até 2008, o Enade era realizado por amostragem 5 , e o Inep elaborava a amostra dos participantes a partir da inscrição, pela própria instituição de ensino superior, dos alunos habilitados a fazer a prova. A participaçáo do estudante selecionado no

\footnotetext{
2 Para uma análise mais ampla sobre as principais alteraçôes ocorridas do Provão ao Enade consultar Verhine, Dantas e Soares (2006).

${ }^{3}$ São considerados alunos ingressantes (primeiro ano do curso) aqueles que, até a data determinada pelo Inep, tiverem concluído entre $7 \%$ e $22 \%$ da carga horária mínima do currículo do curso da IES.

${ }^{4}$ São considerados alunos concluintes (último ano do curso) aqueles que, até a data determinada pelo Inep, tiverem concluído pelo menos $80 \%$ da carga horária mínima do currículo do curso da IES, ou todo aluno que se encontre na possibilidade de concluir o curso no respectivo ano letivo.

${ }^{5}$ Segundo informaçōes do Inep, em 2009, o Enade foi censitário e também o será em 2010.
} 
Enade é condição indispensável para a emissão do histórico escolar, onde é registrada a data em que o aluno realizou o exame.

Portanto, todo aluno selecionado é obrigado a comparecer no dia da prova para, no mínimo, assinar seu nome e devolver o material em branco. Caso contrário, não poderá receber o diploma enquanto não regularizar a situação junto ao Inep, por meio de justificativa ou realizando a prova de formação geral no ano seguinte.

Com base nas notas no Enade dos alunos de cada curso, é gerado o Conceito Enade ${ }^{6}$, um índice de 1 a 5 atribuído aos cursos. Como a mesma prova é aplicada para alunos concluintes e ingressantes dos cursos, é possível usar esses dados para calcular o Indicador de Diferença entre os Desempenhos Observado e Esperado (IDD $)^{7}$ - a diferença entre a nota obtida pelos concluintes e a nota que seria esperada (baseada na nota dos ingressantes). O IDD é, na verdade, uma medida da contribuição do curso para o desempenho de seus estudantes no Enade.

Com resultados do Enade e do IDD somado a um componente de insumos ${ }^{8}$ é construído o Conceito Preliminar de Cursos (CPC) ${ }^{9}$, que possui como função principal a orientação dos avaliadores institucionais e a racionalizaçáo das avaliações in loco na atribuição do Conceito de Curso. O CPC é um índice com escala de 1 a 5 que permite a dispensa dessa avaliação caso o resultado seja maior do que $2^{10}$. Se houver visita in loco, o Conceito de Curso será definido pelos avaliadores. Os cursos com CPC 3 e 4, objetivando melhora desse resultado, podem solicitar a visita, mas, caso o Conceito do Curso divirja do CPC é necessário uma justificação dos motivos.

\footnotetext{
${ }^{6}$ Para detalhes do cálculo do Conceito Enade, ver Nota Técnica do Enade. Disponível em: http://Enade.inep.gov.br/EnadeResultado/site/resultados/pesquisaResultados.faces.

${ }^{7}$ Para detalhes do cálculo do IDD, ver Nota Técnica do IDD. Disponível em: http://www. inep.gov.br/areaigc.

${ }^{8} \mathrm{O}$ componente "insumos" é construído com informaçôes relacionadas à titulação e ao regime de trabalho do corpo docente e à percepçáo dos alunos em relação à infraestrutura do curso e sua organização pedagógica.

9 Para detalhes do cálculo do CPC, ver Nota Técnica do CPC Disponível em: http://Enade. inep.gov.br/EnadeResultado/pdfs/Procedimentos_Metodologicos_Calculo.pdf.

${ }^{10}$ Caso náo fosse instituído o $\mathrm{CPC}$, todos os cursos avaliados pelo Enade deveriam receber visita in loco a cada ciclo trienal. Isso resultaria em cerca de 9.800 visitas por ciclo, perto de 3.260 visitas/ano e aproximadamente 270 visitas/mês, o que torna esse procedimento operacionalmente inviável.
}

92 - Est. Aval. Educ., São Paulo, v. 21, n. 45, p. 87-106, jan./abr. 2010 


\section{ANÁliSE dOS ALUNOS QUE ADOTAM O BOICOTE 3.1 Construçáo da amostra}

Como já descrito, até 2008, o Enade era realizado de forma amostral. Portanto, do total de alunos ingressantes ou concluintes dos cursos de graduaçáo avaliados em determinado ciclo, apenas uma parcela era selecionada para participar da prova. Apesar da obrigatoriedade do exame para a obtençáo do diploma, existe ainda uma parcela de alunos que não comparece para realizá-lo ${ }^{11}$, ficando irregulares com $o$ MEC. Como forma de captar a intenção do aluno em promover o boicote, utilizouse neste estudo apenas os alunos selecionados e presentes na aplicaçáo do exame. Pensou-se, ainda, que a ausência dos alunos poderia representar um modo de insatisfaçáo com o processo avaliativo e isso poderia ser caracterizado também como uma forma de boicote. Mas, uma vez que o exame possui caráter obrigatório e pune os ausentes, essa não seria uma estratégia viável de demonstrar tal insatisfação. Além do que não seria possível diferenciar os alunos insatisfeitos e que adotaram essa estratégia de manifestação dos que, por qualquer outro motivo, gostariam de participar do exame, mas não conseguiram estar presentes no momento da realização.

Apesar de se falar muito em boicote ao Enade, não há uma definição oficial do que pode ser considerado um boicote propriamente dito. No presente estudo, são consideradas duas amostras possíveis referentes aos alunos que teriam aderido ao boicote, a serem comparadas com a amostra total dos participantes do exame.

A primeira amostra de boicote engloba apenas os participantes que colam adesivos, escrevem mensagens ou fazem qualquer tipo de registro contra o exame. Esse grupo é identificado pelos realizadores do exame ${ }^{12}$ pela variável "Tipo de presença na prova" como "Protesto". A segunda amostra engloba os participantes que não responderam a nenhuma questão dos quatro componentes da prova ${ }^{13}$, identificados como "Prova em branco".

Com isso, assume-se que os participantes que deixaram as provas totalmente em branco, juntamente com aqueles que expressaram sua manifestação de forma explícita, não tiveram a intenção de contribuir com o processo avaliativo, o que foi considerado uma forma de boicote.

\footnotetext{
${ }^{11}$ A seção 3.2 aborda esse tema de forma mais ampla.

${ }^{12} \mathrm{O}$ Exame é realizado pelo consórcio formado por Cesgranrio, Fundação Carlos Chagas e Cespe, sendo que cada uma dessas organizaçóes elabora as provas de diferentes cursos.

${ }^{13}$ Os componentes do exame que são levados em consideração para a atribuição do conceito são: Formação Geral - Múltipla Escolha; Formação Geral - Discursiva; Componente Específico - Múltipla Escolha; Componente Específico - Discursiva.
} 


\subsection{Análise Descritiva}

\subsubsection{Ausência às Provas}

Antes de passar à análise da ocorrência de boicotes na prova do Enade, é importante apresentar o tamanho da amostra utilizada, referente aos alunos selecionados e presentes à prova, dentre aqueles habilitados e inscritos pelas respectivas instituições de ensino.

Tabela 1 - Total de alunos selecionados, presentes e ausentes no Enade

\begin{tabular}{cccccc}
\hline Ano & $\begin{array}{c}\text { Total de } \\
\text { Selecionados }\end{array}$ & $\begin{array}{c}\text { Total de } \\
\text { presentes }\end{array}$ & $\begin{array}{c}\text { \% de } \\
\text { presentes }\end{array}$ & $\begin{array}{c}\text { Total de } \\
\text { ausentes }\end{array}$ & $\begin{array}{c}\text { \% de } \\
\text { ausentes }\end{array}$ \\
\hline $\mathbf{2 0 0 5}$ & 323.338 & 277.476 & 85,82 & 45.862 & 14,18 \\
$\mathbf{2 0 0 6}$ & 462.658 & 386.524 & 83,54 & 76.134 & 16,46 \\
\hline $\mathbf{2 0 0 7}$ & 215.419 & 189.614 & 88,02 & 25.805 & 11,98 \\
\hline
\end{tabular}

$\mathrm{Na}$ figura 1, são apresentados os percentuais de ausência de alunos dentre aqueles inscritos e selecionados para realizar a prova.

Figura 1 - Percentual de alunos selecionados ausentes no Enade

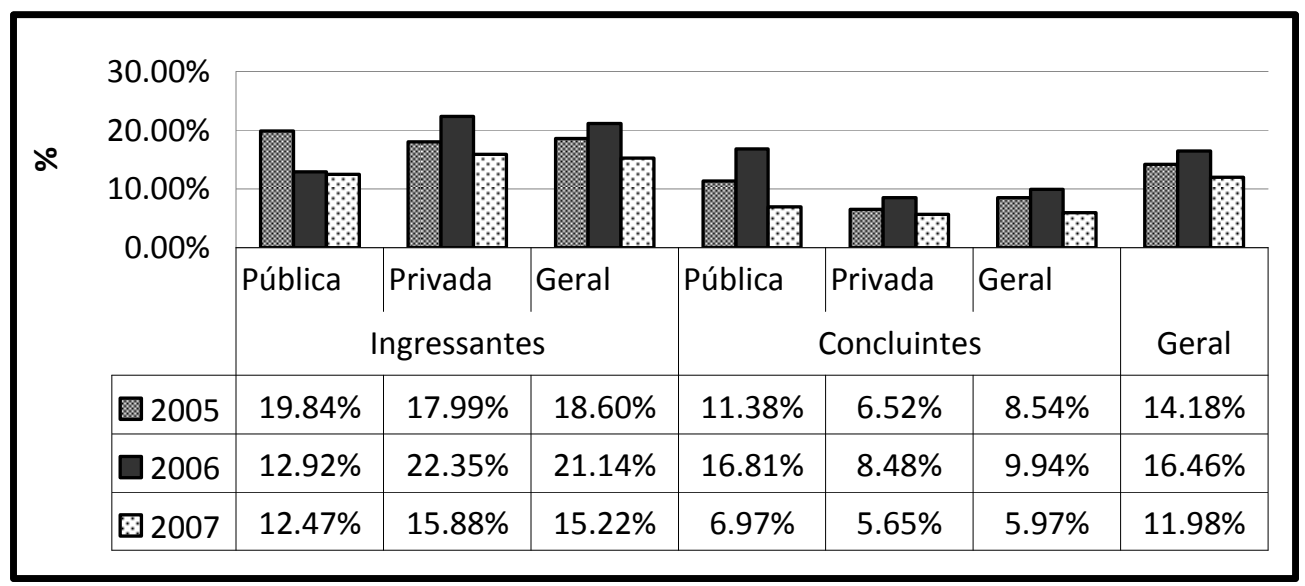

Como pode ser observado, em todos os anos avaliados, o percentual de ausência dos alunos ingressantes foi maior do que o dos concluintes em todas as comparaçôes, com exceção dos alunos concluintes de instituiçóes públicas, em 2006. O percentual de alunos ingressantes que não compareceram ao exame foi especialmente significativo em 2006, passando de $20 \%$. Pode-se supor que essa ausência seja

94 • Est. Aval. Educ., São Paulo, v. 21, n. 45, p. 87-106, jan./abr. 2010 
explicada pelo fato de o aluno ingressante que falta ao exame ter ainda um período de três anos para regularizar a situação junto ao Enade. Cabe ressaltar, ainda, que o aluno irregular não compóe a amostra considerada, ou seja, não contribui para o resultado da avaliação.

Analisando a figura 2, pode-se observar que o período de aplicaçáo do Enade apresentou percentual de ausência muito próximo ao verificado no período de aplicação do Provão, e 2006 destaca-se com o maior percentual de ausência (9,94\%). Para essa comparação, a proporçáo de ausentes no Enade só considera os concluintes, visto que no Provão os ingressantes não eram avaliados.

Figura 2 - Percentual de alunos concluintes ausentes no Provão e no Enade

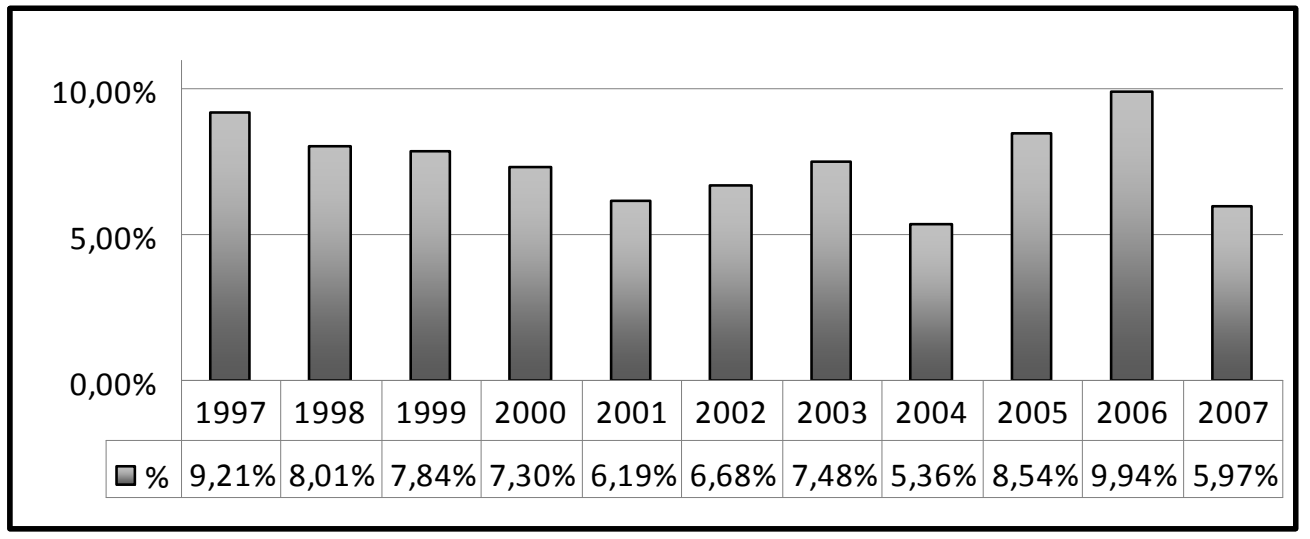

O alto percentual encontrado em 2006 pode estar relacionado aos cursos avaliados nesse ano. Uma vez que na metodologia de avaliação do Provão todos os cursos eram avaliados anualmente, enquanto no Enade a avaliaçáo de cada curso ocorre trienalmente, não foi possível comparar a ausência apresentada nos anos do Enade com os demais anos analisados. Apenas em 2004, cujos cursos foram reavaliados em 2007, pode-se identificar que o percentual de ausência é similar, mostrando que essa tendência comportamental se manteve equivalente. Dessa mesma forma, a comparação de 2005 e 2006 só será válida quando analisados os anos de 2008 e 2009.

\subsubsection{Ocorrências de Boicote}

Como pode ser observado na figura 3, o percentual de boicote nunca foi superior a 3,5\% para o total da população avaliada, em todos os anos de 
aplicaçáa, tanto do Provão (1997 a 2003) quanto do Enade (2004 a 2007). Interessante notar a variabilidade desse percentual quando comparados os anos de realizaçáo do Enade, indicando que esse comportamento pode estar diretamente associado aos cursos avaliados.

Figura 3 - Percentual de boicote (1997 a 2007)

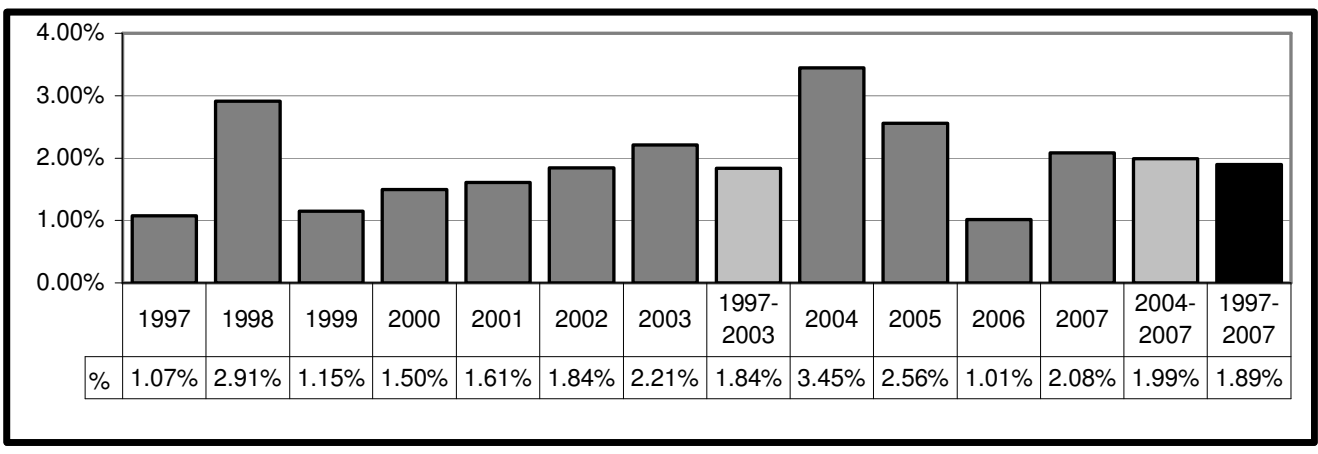

\subsubsection{Modalidades de boicote}

A figura 4 apresenta as modalidades de boicote por tipo de instituiçáo (pública e privada). Nota-se que "Prova em branco" foi a modalidade mais utilizada ao longo do processo avaliativo. Outro fato que pode ser constatado nessa análise é que os alunos das instituiçóes públicas, em quase todos os anos avaliados, utilizaram mais a modalidade de boicote "Protesto" do que os das instituiçóes privadas.

Figura 4 - Modalidade de boicote por ano

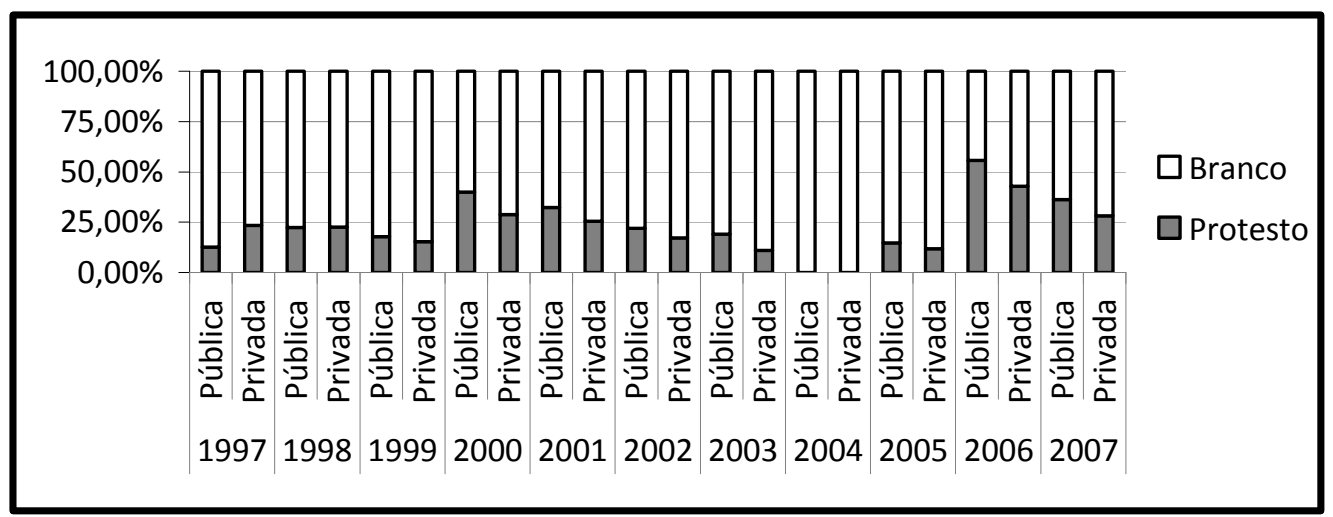

96 - Est. Aval. Educ., São Paulo, v. 21, n. 45, p. 87-106, jan./abr. 2010 


\subsubsection{Análise de boicote por cursos}

A figura 5 exibe o total de boicote dos cursos avaliados em 2005, 2006 e 2007. Apesar de o percentual total de boicote não ultrapassar os 3,5\% dos alunos presentes e selecionados (figura 3), observa-se que ele varia de forma bastante acentuada entre os cursos avaliados. No curso de Ciências Sociais, por exemplo, o percentual chegou a mais de 13\%, enquanto nos cursos de Engenharia Grupo IV (Engenharia Química) e Engenharia Grupo VII (grupo misto I) não houve nenhum boicote registrado.

Figura 5 - Total de boicote por curso (2005, 2006 e 2007)

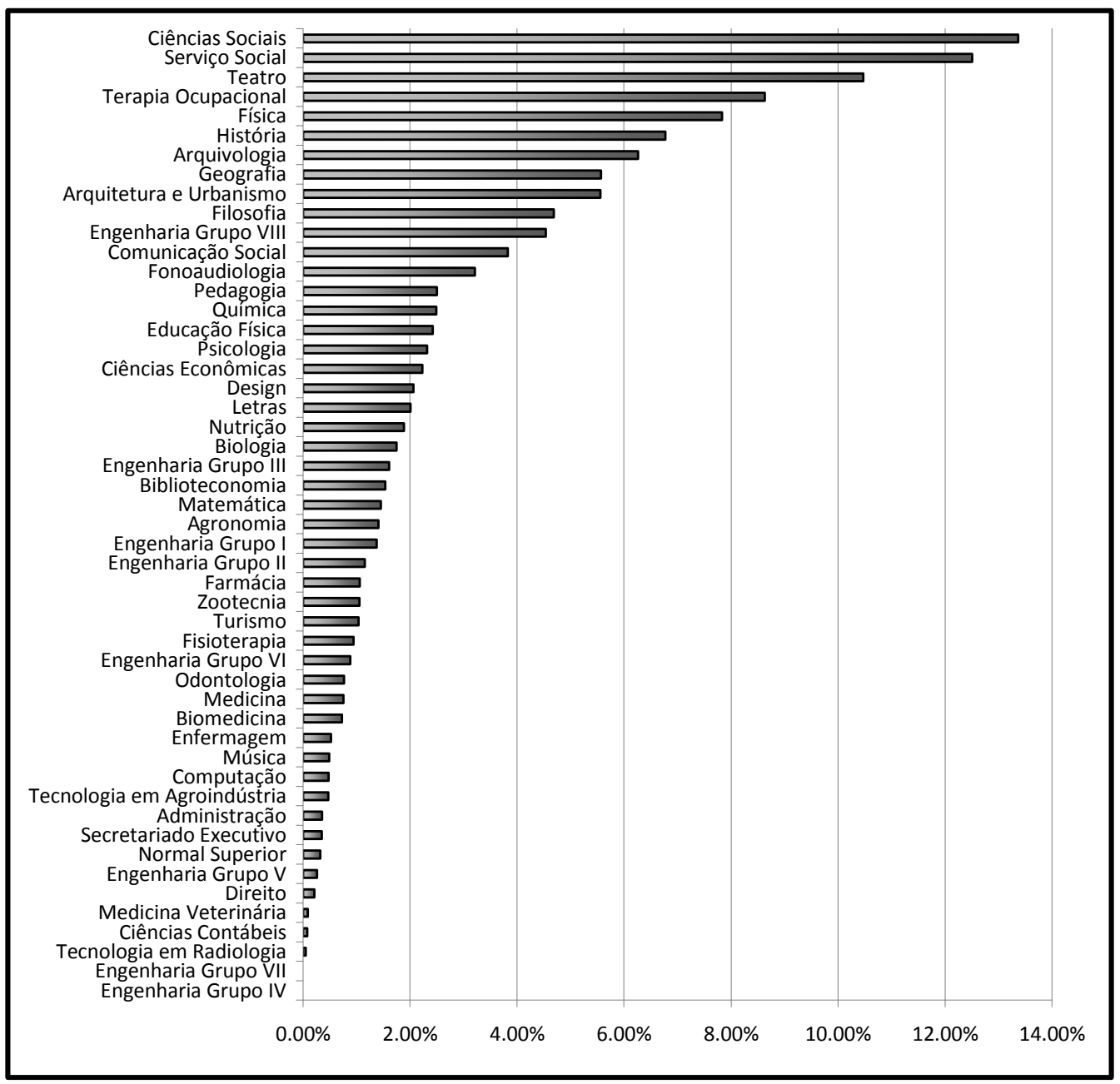

Est. Aval. Educ., São Paulo, v. 21, n. 45, p.87-106, jan./abr. 2010 • 97 


\subsection{Análise Econométrica}

Com o objetivo de verificar as variáveis que poderiam influenciar a probabilidade de boicote dos alunos que participam do Enade, foi realizada uma análise econométrica, utilizando-se a metodologia de regressáo logit. Esse tipo de análise permite identificar o impacto isolado de determinada variável na probabilidade de boicote. Os dados utilizados nessa análise são provenientes dos bancos de dados e resultados do Enade e dos questionários socioeconômicos de 2005, 2006 e 2007.

Como variável dependente, foi construída uma variável binária que assumiu o valor " 1 ", caso o indivíduo tivesse boicotado (foram assumidos neste caso os dois tipos de boicote: protesto e prova em branco), e o valor "0" caso contrário ${ }^{14}$. Como variáveis independentes, foram utilizadas informaçóes pessoais sobre o indivíduo (idade, gênero, estado civil, cor da pele, renda familiar, ocupação, escolaridade dos pais, tipo de escola em que cursou o ensino médio e assuntos que mais lê no jornal), bem como informaçôes sobre a condição do indivíduo no curso (ingressante ou concluinte, regiáo do curso que frequenta, se é ou foi bolsista, dedicação aos estudos, percepção dos aspectos físicos, pedagógicos e curriculares do curso, percepção sobre o domínio dos professores e exigência do curso, contribuição do curso, categoria administrativa da instituição e curso que frequenta).

Os gráficos a seguir apresentam o impacto de cada uma das variáveis independentes de interesse sobre a probabilidade de boicote (só foram consideradas as variáveis estatisticamente significativas com nível de significância mínimo de $0,10)$. Os gráficos foram obtidos a partir do seguinte procedimento: considerouse os coeficientes das variáveis provenientes do logit inicial. A partir daí, atribuiu-se o nível mínimo da variável que seria analisada para todos os indivíduos da amostra. Calculou-se entáo a probabilidade de boicote de cada indivíduo e obteve-se a média dessas probabilidades. Esse resultado mostrou qual era a média das probabilidades de boicote caso todos os indivíduos possuíssem o nível mínimo da variável analisada. Então, atribuiu-se um nível acima do mínimo da variável analisada a todos os indivíduos da amostra. Novamente foram calcu-

\footnotetext{
${ }^{14}$ As informaçôes referentes aos indivíduos dos cursos Engenharia Grupo IV (Eng. Química), Engenharia Grupo V (Eng. Materiais), Engenharia Grupo VII (Eng. Grupo Misto I), Tecnologia em Radiologia e Tecnologia em Agroindústria foram excluídas da análise por apresentarem um número muito reduzido de boicote.
}

98 - Est. Aval. Educ., São Paulo, v. 21, n. 45, p. 87-106, jan./abr. 2010 
ladas as probabilidades individuais de boicote. Com esses resultados, obteve-se a média das probabilidades de boicote caso todos os indivíduos possuíssem um nível a mais nessa característica analisada. E assim sucessivamente até o nível mais alto do atributo que foi considerado.

\subsubsection{Resultados das variáveis referentes à IES e à condição do aluno na IES}

Um fator importante na influência da probabilidade de boicote é a categoria administrativa da IES. Os resultados mostram que a diferença desse fator isolado representa um incremento de cerca de 2,5 pontos percentuais na probabilidade desse aluno boicotar.

Quando a influência da situaçáo do aluno foi analisada, notou-se que o fato de o aluno ser ingressante aumenta a probabilidade de boicote, apesar do aumento não ser muito representativo.

Figura 6 - Probabilidade de boicote por categoria administrativa da IES

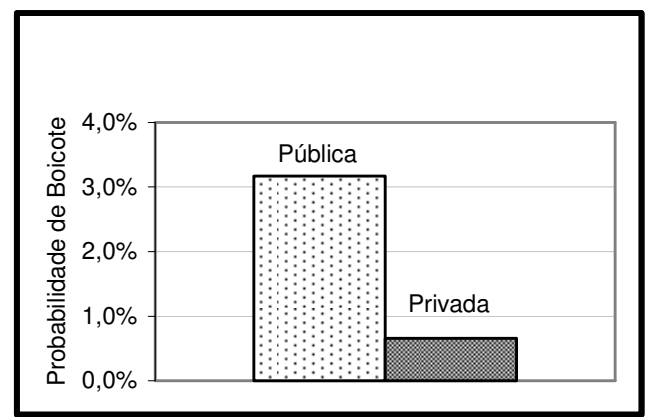

Figura 7 - Probabilidade de boicote por situação do aluno

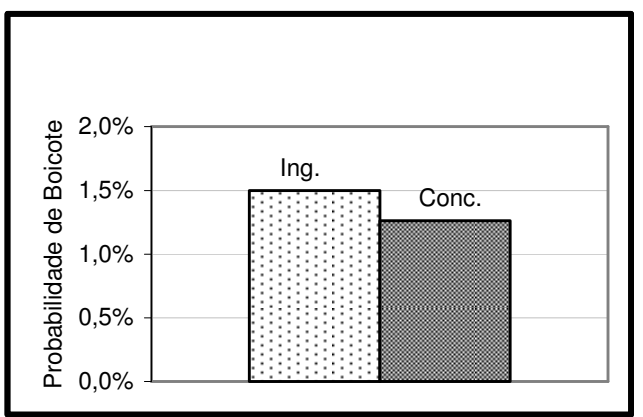

Outra análise de interesse foi avaliar a probabilidade de boicote por curso. Pode-se observar claramente que há grande variação de probabilidade de boicote quando são analisados os cursos individualmente. 
Figura 8 - Probabilidade de boicote por curso

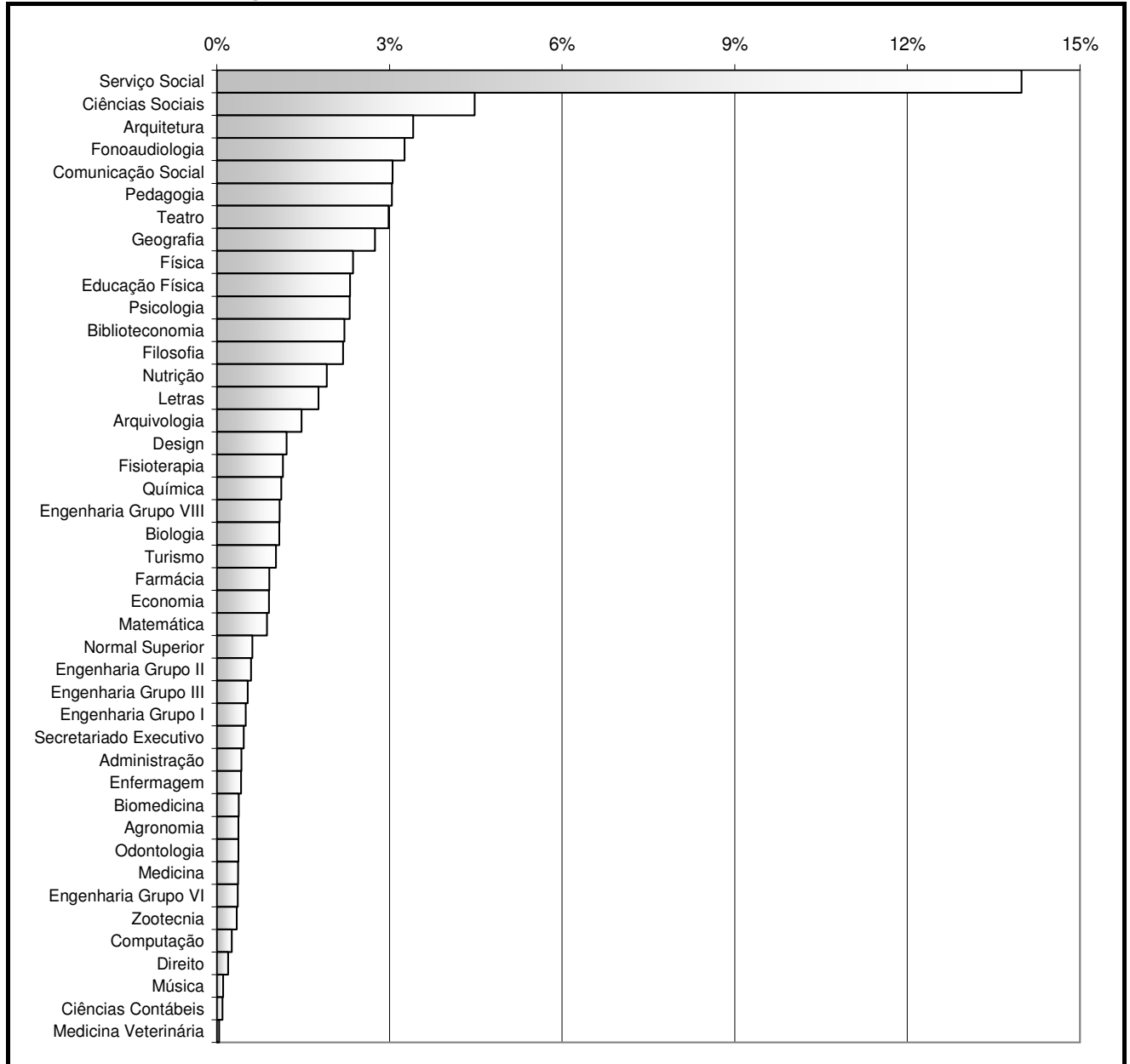

É interessante notar a diferença existente entre os gráficos apresentados nas figuras 8 e $5 . \mathrm{Na}$ figura 8 , a influência dos cursos na probabilidade de boicote está controlada por diversas outras variáveis, enquanto na figura 5 é apresentada a porcentagem de boicote por curso sem qualquer tipo de controle. Para explicitar essa diferença, pode-se tomar o curso de Arquivologia como exemplo: de acordo com a figura 5 , esse era o $7^{\circ}$ curso com maior porcentagem de boicote. Na figura 8, entretanto, ele passou para a $16^{a}$ posição na probabilidade de boicote. Como esse curso possui apenas alunos em instituiçóes públicas, o resultado da figura 5 pode mostrar não só a influência do curso no boicote, mas também a influência de o curso ser

100 • Est. Aval. Educ., São Paulo, v. 21, n. 45, p. 87-106, jan./abr. 2010 
$100 \%$ oferecido por IES públicas, uma vez que esse fato, por si só, já aumenta a probabilidade de boicote, conforme revela a figura 6. Com a análise econométrica, o efeito "pública" já foi captado na variável de controle, e assim o impacto isolado do curso torna-se mais "puro". Essa interpretação serve para todas as outras variáveis do modelo.

\subsubsection{Variáveis referentes à condição socioeconômica do aluno}

A análise das variáveis referentes à condição socioeconômica tem por objetivo identificar as características pessoais de cada aluno que influenciam a probabilidade de esse aluno boicotar. Observa-se nos gráficos seguintes que essas características, em geral, não exercem grande influência nessa probabilidade.

Entre as características pessoais, a renda familiar e a categoria administrativa da escola de ensino médio que o aluno frequentou são as variáveis com maior peso na influência da probabilidade de boicote do aluno. Os resultados a seguir apontam que quanto maior a renda familiar, maior será a probabilidade de o aluno boicotar, bem como o fato de o aluno ter frequentado a maior parte do ensino médio em escola privada. A escolaridade dos pais mostra que quanto mais escolarizados forem, maior a probabilidade de boicote. Outra variável de característica pessoal que também apresenta certa influência na probabilidade de boicote, mas de maneira mais amena, é a situação ocupacional do aluno. $O$ fato de o aluno não trabalhar apresenta influência levemente maior na probabilidade de boicote.

Figura 9 - Influência da renda na probabilidade de boicote

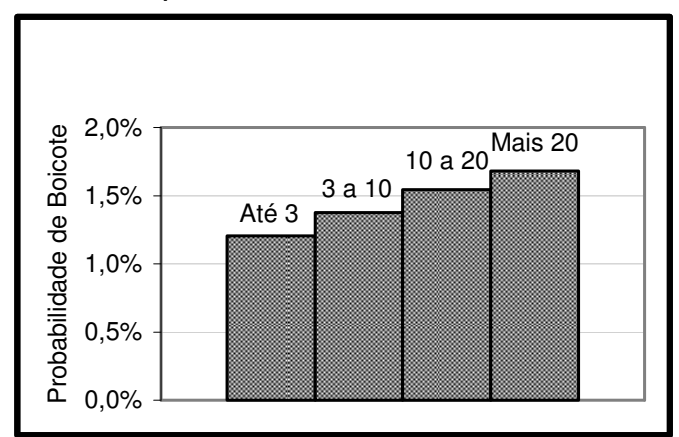

Figura 10 - Influência do local onde cursou o ensino médio na probabilidade de boicote

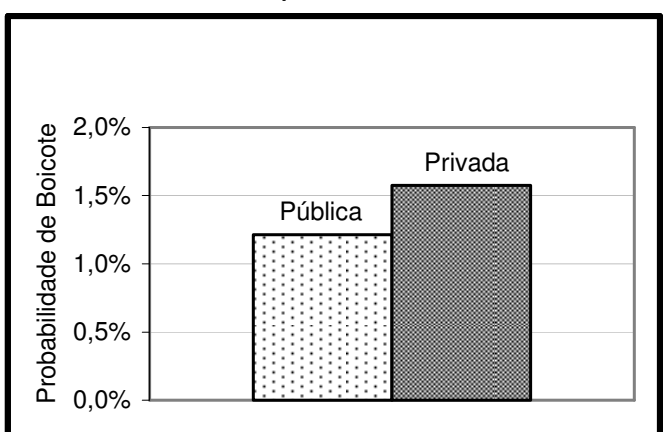


Figura 11 - Influência da escolaridade do pai na probabilidade de boicote

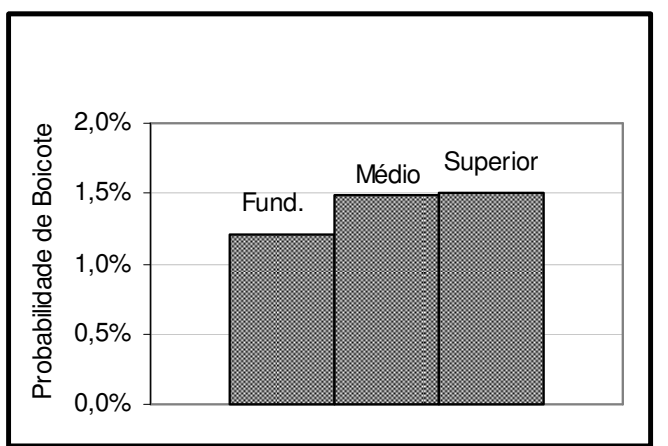

Figura 12 - Influência da situação ocupacional na probabilidade de boicote

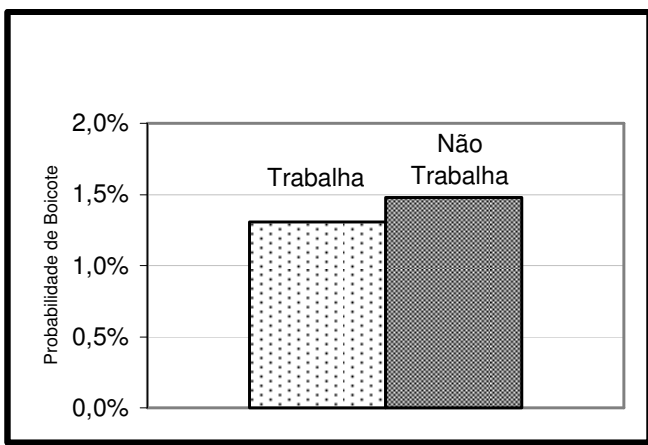

\subsubsection{Variáveis referentes à avaliação do aluno à IES}

A seguir, é possível observar que quanto pior a avaliação do aluno nos quesitos instalaçóes físicas, equipamentos disponíveis, equipamentos de laboratório e currículo do curso, maior a probabilidade de boicote. Essa análise pode indicar que os alunos que boicotam o exame utilizam-se desses meios como forma de demonstrar sua insatisfação com o curso e/ou a instituição.

Figura 13 - Influência da avaliação das instalações físicas na probabilidade de boicote

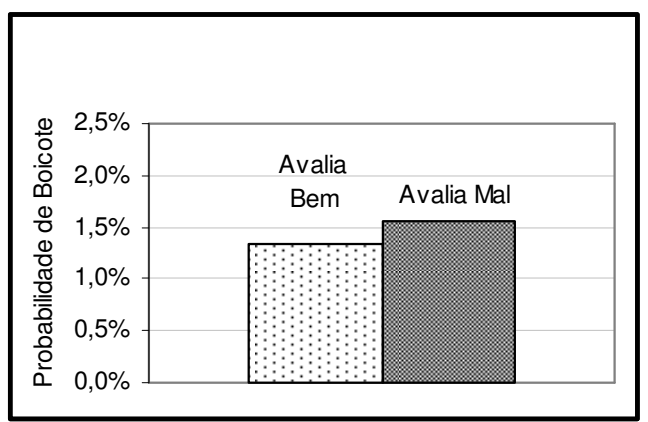

Figura 14 - Influência da avaliação dos equipamentos disponíveis na probabilidade de boicote

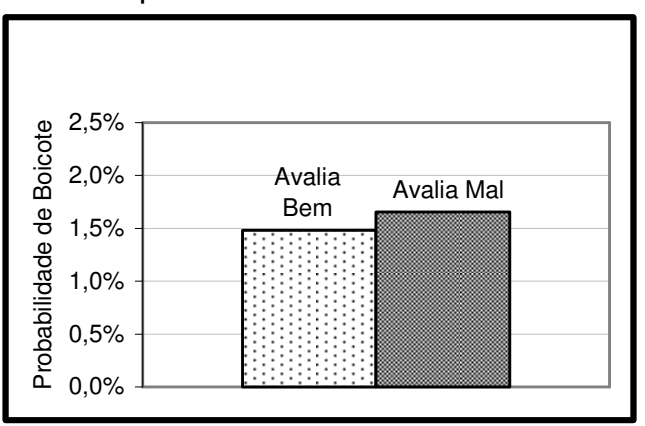

102 - Est. Aval. Educ., São Paulo, v. 21, n. 45, p. 87-106, jan./abr. 2010 
Figura 15 - Influência da avaliação dos equipamentos de laboratório na probabilidade de boicote

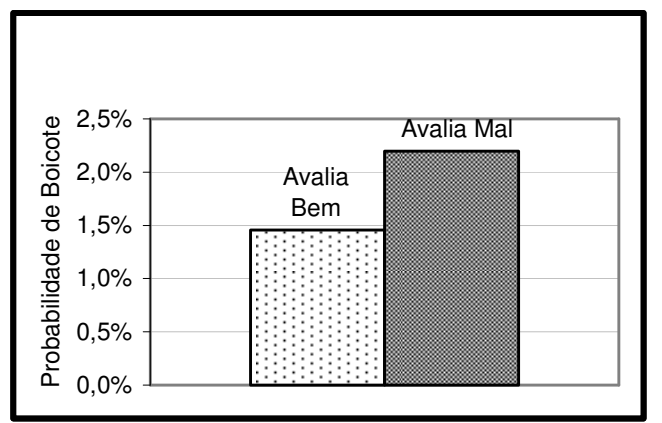

Figura 16 - Influência da avaliação do currículo na probabilidade de boicote

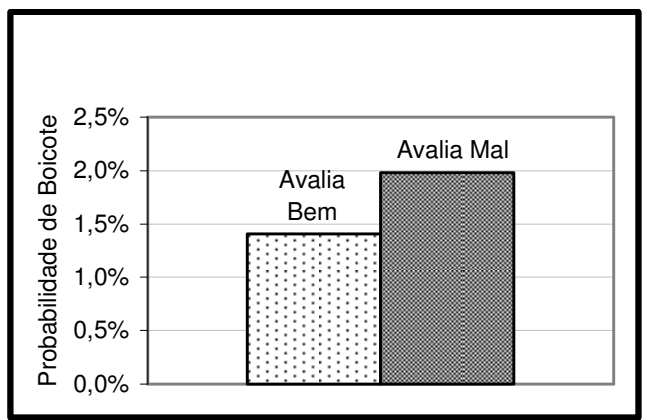

Outra análise que despertou bastante interesse foi com relação à evolução do boicote ao longo do tempo e a identificação de alguma alteração de comportamento, influenciada por evento específico em um dos anos da análise (passagem do Provão para o Enade ou forte campanha "pró-boicote" de algum movimento estudantil, por exemplo).

A princípio, pensou-se em agrupar ao banco de dados inicial - aquele com os dados de 2005, 2006 a 2007 - as mesmas informaçóes levantadas para o período 1997 a 2004. Porém, alguns problemas de identificação de variáveis e inconsistência de informaçóes foram detectados e, optou-se, assim, por construir um novo banco de dados para os anos de 1999 a 2007. As principais diferenças desse novo banco de dados com o banco utilizado nas análises anteriores são a inclusão de uma variável binária (dummy) de ano e de uma nova variável de situação ocupacional, informando se o indivíduo trabalha ou já trabalhou durante o período do curso (antes essa variável informava se o indivíduo trabalhava no momento do exame) e a exclusão das variáveis de idade, estado civil, se é ou foi bolsista, assuntos que mais lê no jornal, dedicação acadêmica e percepção aos aspectos físicos, pedagógicos e curriculares do curso.

Para facilitar e exposição desses resultados, adotou-se a mesma metodologia gráfica utilizada anteriormente, e os valores encontrados estáo representados na figura 17. 
Figura 17 - Probabilidade de boicote ao longo dos anos

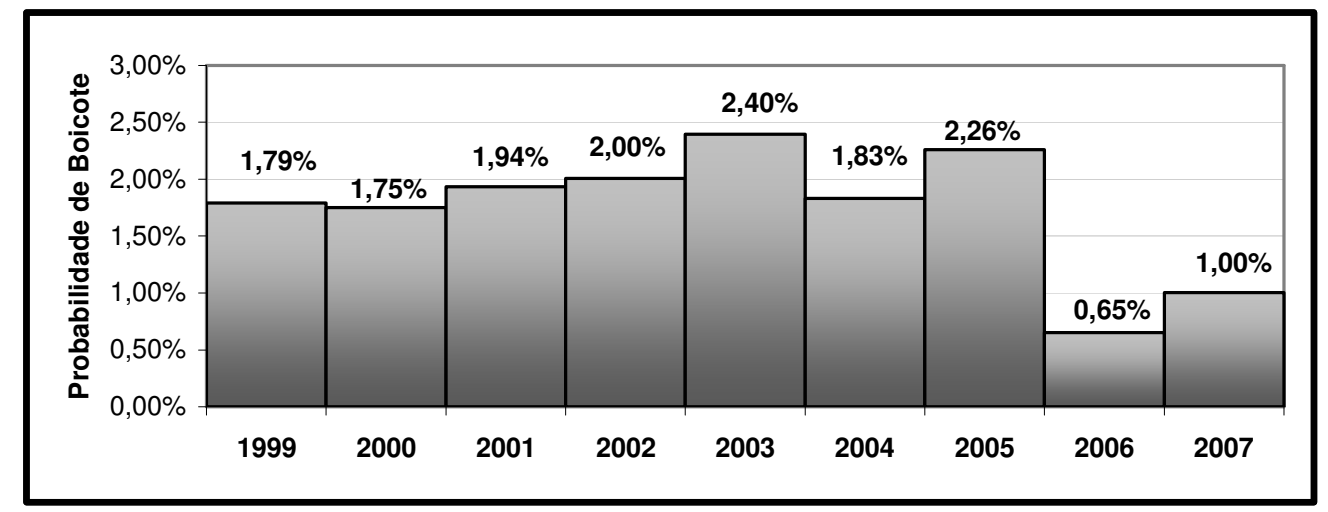

Identificou-se um padrão relativamente constante de boicote no decorrer de 1999 a 2005, sem que houvesse alteração tendencial de comportamento logo após a alteração do sistema de avaliação Provão para Enade (de 2003 para 2004). Interessante notar que essa mudança ocorreu nos anos de 2006 e 2007, mostrando que, pelo menos nos dois últimos anos de Enade, a influência isolada do fator "ano" assumiu uma dimensão bastante inferior à demonstrada nos anos anteriores.

\section{CONSIDERAÇÕES FINAIS}

Este trabalho teve como objetivo analisar o fenômeno popularmente denominado de boicote aos exames que compóem o sistema de avaliação do ensino superior, dando ênfase ao Exame Nacional de Desempenho dos Estudantes (Enade).

Como pôde ser observado, esse comportamento, de forma geral, possui uma dimensão reduzida, nunca tendo ultrapassado 3,5\% da população avaliada, mas quando analisado por curso, verificou-se grande variação de incidência, com alguns cursos sendo claramente mais afetados por esse fenômeno.

Também puderam ser identificadas, neste estudo, as diferentes influências que algumas variáveis possuem na probabilidade de boicote. Observou-se que o curso que o aluno frequenta pode influenciar nessa probabilidade de forma muito variável. Assim, um aluno que frequenta o curso de Serviço Social, por exemplo, possui maior probabilidade de boicotar que um aluno do curso de Medicina Veterinária ou Ciências Contábeis em cerca de 13 pontos percentuais. Além da variável curso, a categoria administrativa da instituição (pública ou privada), a renda familiar e a categoria administrativa da escola em que o estudante cursou o ensino médio se destacaram das demais na influência da probabilidade de boicote dos alunos.

104 • Est. Aval. Educ., São Paulo, v. 21, n. 45, p. 87-106, jan./abr. 2010 
Outro interessante resultado identificado foi a relação entre a avaliação dos alunos quanto ao curso e/ou IES que frequentam e a probabilidade de boicote. Foi observado que os alunos que avaliam negativamente os aspectos físicos e curriculares possuem maior probabilidade de boicote do que os alunos que fazem uma avaliação positiva. Esse resultado pode indicar que os estudantes que boicotam o fazem para demonstrar insatisfação com o curso e/ou IES.

Por fim, na análise temporal, verificou-se que não houve alteração no comportamento do ato de boicotar dos alunos, na transição do Provão para o Enade (de 2003 para 2004).

A busca da descrição, da compreensão e da explicação do fenômeno "boicote" levou a diferentes possibilidades e escolhas para a produção deste material. Mesmo considerando a escassez de bibliografia específica, o presente artigo pretendeu elucidar as possíveis correlaçóes das diferentes variáveis analisadas com o ato de boicotar. Futuras consideraçôes sobre o tema poderão verificar a intensidade desse comportamento, e, a partir daí, atribuir conclusóes mais precisas sobre a tendência desse fenômeno.

\section{REFERÊNCIAS BIBLIOGRÁFICAS}

BRASIL. Leis e decretos. Lei n. ${ }^{\circ}$ 9.394. Lei de Diretrizes e Bases da Educação Nacional. DOU, 20 dez. 1996. Disponível em: <http:// www.planalto.gov.br/ccivil/LEIS/L9394.htm>. Acesso em: 05 mar. 2009.

Ministério da Educação. Sistema

Nacional de Avaliação da Educação Superior - Sinaes: bases para uma nova proposta de avaliação da educação superior. Brasília, 2003.

DIAS, C. L.; HORIGUELA, M. L. M.; MARCHELLI, P. S. Políticas para avaliação da qualidade do ensino superior no Brasil: um balanço crítico. Educação e Pesquisa, v. 32, n. 3, dez. 2006. Disponível em: <http://www.scielo. br/scielo.php?script=sci_arttext\&pid=S1517$97022006000300002 \& \mathrm{lng}=\mathrm{pt} \& \mathrm{nrm}=\mathrm{iso}>$. Acesso em: 07 abr. 2009.

HARVEY, L.; NEWTON, J. Transforming quality evaluation. Quality in Higher Education, v.10, n.

2, p.149-165, jul. 2004.

PAIVA, G. S. Avaliação do desempenho dos estudantes da educação superior: a questão da equidade e obrigatoriedade no Provão e Enade. Ensaio: avaliação e políticas públicas em educação, v. 16, n. 58, mar. 2008. Disponível em $<$ http://www.scielo.br/scielo.php?script=sci_ arttext\&pid=S0104-40362008000100003\&lng =pt\&nrm=iso>. Acesso em: 09 mar. 2009.

UNE propõe boicote ao Enade mais uma vez. O Estado de S. Paulo, São Paulo, 7 nov. 2008. Vida \& Educação. Disponível em: <http://www. estadao.com.br/vidae/not_vid274236,0.htm>. Acesso em: 25 fev. 2009.

VERHINE, R. E.; DANTAS, L. M. V.; SOARES, J. F. Do Provão ao Enade: uma análise comparativa dos exames nacionais utilizados no ensino superior brasileiro. Ensaio: avaliação e políticas públicas em educação, v. 14, p. 291-310, jul./set. 2006.

Recebido em: outubro 2009

Aprovado para publicação em: março 2010 